\title{
Couples experiences of using DemPower in everyday life
}

DOI:

10.1108/QAOA-10-2019-0059

\section{Document Version}

Accepted author manuscript

Link to publication record in Manchester Research Explorer

\section{Citation for published version (APA):}

Bielsten, T., Keady, J., Kullberg, A., Lasrado, R., \& Hellström, I. (2020). Couples experiences of using DemPower in everyday life. Quality in Ageing and Older Adults. https://doi.org/10.1108/QAOA-10-2019-0059

\section{Published in:}

Quality in Ageing and Older Adults

\section{Citing this paper}

Please note that where the full-text provided on Manchester Research Explorer is the Author Accepted Manuscript or Proof version this may differ from the final Published version. If citing, it is advised that you check and use the publisher's definitive version.

\section{General rights}

Copyright and moral rights for the publications made accessible in the Research Explorer are retained by the authors and/or other copyright owners and it is a condition of accessing publications that users recognise and abide by the legal requirements associated with these rights.

\section{Takedown policy}

If you believe that this document breaches copyright please refer to the University of Manchester's Takedown Procedures [http://man.ac.uk/04Y6Bo] or contact uml.scholarlycommunications@manchester.ac.uk providing relevant details, so we can investigate your claim.

\section{OPEN ACCESS}




\section{Couples experiences of using DemPower in everyday life}

\begin{tabular}{|r|l|}
\hline Journal: & Quality in Ageing and Older Adults \\
\hline Manuscript ID & QAOA-10-2019-0059.R2 \\
\hline Manuscript Type: & Research Paper \\
\hline Keywords: & $\begin{array}{l}\text { Application, Couples, Dementia, Information and Communication } \\
\text { Technology, Intervention, Self-management }\end{array}$ \\
\hline
\end{tabular}


1 Couples experiences of using [app name] in everyday life

2

3 Introduction: Interventions aimed at couples where one partner has dementia are often

4 targeting burden, depression and cognitive function and do not focus on relationship and

5 interpersonal issues. Furthermore, interventions within this population do not seem to

6 have embraced a salutogenic and authentic dyadic approach where both partners'

7 experiences are considered. In order to address this gap, we developed a couple-

8 management app, [app name], which was piloted and tested among couples where one

9 partner has dementia living at home. Aim: This study explores couples' experiences of

10 engaging with the app [app name]. Methods: Semi-structured interviews with couples

11 were analysed using thematic analysis. Findings: The findings resulted in the themes

12 Growth of the relationship; We are not alone; and Positive approach. Discussion: The

13 findings indicated that the experiences of a salutogenic and dyadic intervention can contribute to feelings of empowerment, satisfaction of couples' achievements and a sense of support through peers and with the app itself. Technology; Intervention; Self-management

19 In Sweden, it is estimated that around 160,000 people are living with dementia and this

20 demographic trend will nearly double in the next 20 years (National Board of Health 21 and Welfare, 2014). Most people with dementia in Sweden live at home and require 22 homecare services and support (Official Report of the Swedish Government, 2016).

23 This trend also applies to other high-income countries where two-thirds of people with 24 dementia live in their own homes (Alzheimer's Disease International, 2013). 
Many people with dementia live together with their partner who often becomes

an informal caregiver. According to Alzheimer's Disease International (2009), 85\% of couples where one partner has dementia living at home, need some form of support to manage their daily life. However, support provided for couples is often task-oriented, and often focused on psychosocial support for the partner without dementia, such as via support groups and education-based material (Alzheimer's Disease International, 2016).

Much of the support for people with dementia and partners, including couple-based support, is largely absent and where it does exist, it seems to lack a genuine dyadic approach where relationship factors are acknowledged (Author, 2017a). Furthermore, couples' relationships where one partner has dementia are often described negatively (see for example Ablitt, Jones \& Muers, 2009; Allen, Curran, Duggan, Cryan, Chorcora 'et al. 2017) with outcomes of interventions focussed on measuring caregiver burden, depressive symptoms and cognitive functioning (Purkis \& Ceci, 2015).

Although the aspect of reducing negative outcomes are important, and that symptoms of dementia are a threat to wellbeing as a couple, arguably it is of greater importance to target support towards the positive elements of the couple's relationship and everyday life. In fact, relationship quality has been highlighted as a key factor for the prevention of negative outcomes (Ablitt et al. 2009; Allen et al. 2017), including in three recent reviews of the literature on this topic area (Author, $2017 \mathrm{a}, \mathrm{b}$; Conway, Watson, Tatangelo \& McCabe, 2018). This makes one wonder why relationship quality and support in couples' day-to-day life together are not the sole targets of the intervention(s) (see also Heehyul, Townsend, Whitlatch, Dilworth-Anderson, 2017; Sinclair, Auret, Gersbach, Hogan, Bucks, Clayton, Agar \& Kurrle, 2018).

Over the past decade, the focus on a salutogenic approach (from the term salutogenesis, i.e focus on health not illness) within the treatment of chronic conditions, 
50 has rapidly increased. Alongside this, an ever increasing number of self-management

51 resources have become available for people living with chronic conditions. Here, selfmanagement aims to improve health for those concerned and is targeted for use at the time and place it best suits the person (Barlow, Wright, Sheasby, Turner \& Hainsworth, 2002). Many of the available self-management resources are digital, such as those accessible online (Chiu \& Eysenbach, 2011; Grady \& Gough, 2015), although selfmanagement and digital interventions have not yet been implemented as an integral part of the care of people with dementia (Huis in het Veld, Francke, Verkaik \& van Meijel, 2018). Some of the reasons for this might be that the views of self-management techniques are clearly linked to medicine and symptom control (Martin, Turner,

60 Wallace, Choudhry \& Bradbury, 2013) with Ibrahim et al. (2017) recently suggesting that people living with dementia should not be given too much responsibility over their personal situation due to their on-going cognitive decline. However, this restricted application completely misses the point, as a core philosophy of self-management is that it should not solely focus on symptom control alone and, instead, target the individual's relationships in order to meet the challenges of everyday life (Author 2017b; Martin et al, 2013). Accordingly, there is a clear gap in both the literature and knowledge about a dyadic, salutogenic and self-management approach directed towards couples where one partner has dementia living at home. It is to this area that this article will now turn.

Bridging the dyadic, salutogenic and self-management approach together

\section{0 through [app name]}

Our aim with the [app name] application was to develop a home-based intervention constructed from self-management techniques and with a dyadic and salutogenic approach that couples could engage in when it suited them best. This intervention is referred to as a couple-management app. The objectives of [app name] 
75 were threefold: i) to help couples focus on the everyday activities they can still do rather

76

77 on what they are no longer able to do; ii) to reflect upon the strengths of the couples relationship and help couples to find ways to tackle daily activities together' and iii) to archive reflections, meaningful moments, and memories the way they would like them to be remembered and stored. The contents of [app name] are structured under the four themes "Home and Neighbourhood", "Meaningful activities and Relationships", "Meeting, Sharing and Caring in your neighbourhood" and "Managing emotions, Communication and Approach" with related sub-headings and sections. The four themes and sections in [app name] are introduced using storyboard techniques with a voiceover, followed by video clips of couples sharing their experiences of living with dementia as a couple. The video clips are based on real-life experiences of couples living with dementia where they share their relationship and everyday life. [app name] makes suggestions for activities under each section. Examples of some activities include games, links to useful information, taking photographs, writing reflections, and discussing emotions and the couples' approach to their relationship and daily life. For more information about the development and content of the [app name] see Author (2018a) and Author (2018b). .
Aim
The aim of this study was to explore the experiences of using the application [app name] among couples where one partner has dementia living at home.

\section{Method}

\section{Participants and procedure}


98 study (Author, 2018a). Inclusion criteria were: couples where one partner has a

99 diagnosis of dementia living at home and who have been in a long-term relationship for

100 two or more years. When follow-up data collection was conducted for the feasibility

101 study, couples were asked if they were interested in participating in an interview study

102 about their experiences of using [app name] [the present study]. Couples received an

103 information sheet about the study at that occasion and a new appointment for the

104 interview was scheduled. Recruitment was made by asking the couples to participate in

105 the order that they completed the feasibility study. In total, eight couples agreed to

106 participate, although two couples later declined due to traveling at the time for the

107 interviews. Six couples therefore participated in the present study and their

108 characteristics are displayed in Table 1.

Please insert table 1 here

\section{Data collection}

111 Interviews took place approximately one week after the information sheet was handed

112 out. All six couples chose to do the interview in their own homes. Interviews varied in

113 length between 20 - 45 minutes. Data consisted of six semi structured interviews and

114 the interview guide is displayed in Table 2. The first author, with several years of

115 experience of communication with people with dementia and their family members,

116 conducted all the interviews. Written informed consent was collected from all

117 individuals before the interview started. Interviews were audio recorded and transcribed

118 verbatim by the first author. 


\section{Analysis}

121 Thematic analysis was used to analyse the data (Braun \& Clarke, 2012). Thematic

122 analysis was conducted by following the stepped process; step 1, where we read the

123 transcribed data several times to gain an overall view of the raw data - here, we marked

124 initial ideas for codes; step 2 refers to coding the data and where we applied

125 descriptions of the data to sequences in order to organise it; in step 3 we clustered codes

126 together in order to form subthemes of the extracts associated to each other; in step 4 we

127 reviewed and refined the subthemes and created main themes as overarching a titles for

128 the corresponding sub themes; step 5 is the last step where the data is reported.

129 Interviews were held in Swedish and data were initially discussed between the Swedish

130 authors to ensure transparency and consictency. After the data had been translated into

131 English the data were discussed within the whole research group.

132

\section{Ethical considerations}

134 The study was given ethical approval by the [name of ethics committee].Participating

135 couples received relevant oral and written information about the study and that they

136 could withdraw from the study at any time. Written and verbal consent was collected

137 from the couples and all data were kept confidential (World Medical Association,

138 2013). To ensure that both individuals in the dyad consented to take part in the study, it

139 was important that the first author actively asked for consent throughout the study, a

140 process that enabled couples to make informed decisions from the start to the

141 completion of the study (Dewing, 2008). This required that the researcher was

142 responsive and sensitive to changing needs. This was important as despite information

143 about voluntary participation, there could be underlying power structures within the

144 relationship that may have influenced the couples'contribution and agreement to take 
145 part (Braybrook, Mróz, Robertson, White \& Milnes, 2017). Moreover, the first author

146 and the couples taking part in this separate follow-on study had already met during the

147 feasibility study of [app name] and it was therefore important that each person within

148 the dyad was given time to reflect upon their decision to take part.

\section{Findings}

150 The findings of this study resulted in three themes: (1) Growth of the relationship, (2)

151 We are not alone and (3) Positive approach.

\section{Theme 1: Growth of the relationship}

153 Couples shared that dementia is a condition that affected them both within all

154 perspectives of their everyday life together and their relationship. They discussed that

155 they considered it somehow as a dyadic condition that could be addressed by discussing 156 their situation in [app name]:

"The app handles a lot of issues related to couple relationship and it is without doubt that you are two with the disease in this disease" Couple 1 (C1)

163 As seen in the above quotations, it seemed to be secondary as to who had the dementia,

164 and more importance was placed upon supporting one another and adjusting to the 165 changing roles and routines that came with the onset of dementia. Couples expressed

166 that the underlying structures of the relationship had changed. Within some couples,

167 both partners felt that their relationship had developed and become more equal, and that 168 the love that was present in their relationship was a powerful force in helping to adjust 
169 to changing circumstances. Sharing such emotions had an affirming and empowering

170 affect and couples validated each other's experiences, as the following slice of data

171 attests:

178 One of the wives, of the two couples described above (C5), said that before her

179 husband had been diagnosed with dementia, he was always 'a leader' and always knew

180 'what to do' and how 'to solve things'. In their current situation, his wife had now

181 taken over many decisions and contacts with authorities that her husband used to

182 manage. In this particular relationship, the husband reported this new-found situation as

183 'pleasant' and seemed to welcome this mutually supportive act. Within the other couple

184 mentioned above (C3), the husband had a hard time accepting change in roles in the

185 beginning but had now accepted it and found it peaceful to not have to be in charge all 186 the time.

187 Couples in the study discussed the fact that they had rarely sat down to talk and

188 reflect upon their situation before using [app name]. Sitting down together to talk could,

189 in itself, contribute towards a sense of closeness and openness. Both partners could then

190 share their frustration about the situation with one another, and not keep things to

191 themselves or share their real feelings outside of the dyadic relationship. The couples

192 felt that using the app had helped their personal relationship and had been a positive

193 experience although it had initially felt 'a bit uncomfortable' (C3). By focussing on [app

194 name], the app seemed to free up the couple's emotions and enable them to talk openly 
195 and honestly together about their real feelings and emotions about living with dementia

196 and the consequences it had for them both, as summarised below:

Couples expressed that they benefited from discussing their communication. They

described it as useful and satisfying to be able to talk about communication in a

conflict-free situation. Recognizing frustration and own shortcomings could be

liberating:

"We talked about conflicts and stress, the fourth chapter. And how we experience that ... I have not dared before ..., I have occassionally said that I

213 Couples had tried new things through the activities of [app name]. Several activities

214 contributed to closeness, especially the suggestion of choosing a song from a music list

215 and express their love for each other. Couples that chose to dance during their selected

216 song expressed that the dance took them back in time and they felt that nothing had

217 really changed in the foundation of their relationship:

218 "And the dance, as we did, was to come back to this feeling, and you were 219 very happy and this I hope we do again...that we actually decide that we are taking a dance, because it's getting back to the closeness we once had" $\mathrm{C} 3$ 
221 The fact that the couple sat next to each other when engaging in [app name] gave them

222

223

224

225

226

227

228

229

230

231

232

233

234

235

236

237

238

239

240

241

242

243

244 return to in the future:

"When we went through it (the app), then it was like this, that I was sitting on that chair and you were sitting on that, and then it was the questions then, so we became closer, I think" C3

\section{Theme 2: We are not alone}

The data suggested that couples enjoyed watching the videos of other couples in the [app name] app as it made them feel that they were not alone with the situation.

Furthermore, couples also found comfort in the videos as a learning experience in how to manage their everyday life, getting tips and advice on how this may be achieved, as these two quotations reveal:

"When you saw these videos of the couples who were talking, you did not feel alone, you could learn from that they say so and that they have solved it like that, they do so to each other..." C5

"Yes, they (videos) calmed us a little, I think. Although there were actors in videos, it calmed me anyway. And they were so nice to each other, I think it gave a lot about how I, as a relative, should behave" $\mathrm{C} 3$

Couples felt that they were cared for through the support in [app name] and that "someone" really had made an effort to help them in their daily life. They also found [app name] helpful overall and that the app had introduced them to a lot of information and advice, some of which they could use in the present day and some that they could 
245

246

247

248

249

250

251

252

253

254

255

256

257

258

259

260

261

262

263

264

265

266

267

268

269

270

"Many things are good to know that they exist and it is good that someone has thought about it and comes up with suggestions, practical suggestions that can be a seed for something that you can use later. I think, there were plenty of seeds" C1

\section{Theme 3: Positive approach}

Couples had embraced the strategy of living in the moment and when discussing this in [app name], it gave them an assurance that their strategy was the right way to go. They saw "living in the moment" as their best tip for other couples and also to normalise and to embrace the future:

"Much of what the app said was to live in the present and that's the thing" $\mathrm{C} 2$

"Our tip is to live in the present and make the most of the time. Then, it (dementia) is not something you die from in two days so you do not have to hurry and you do not have to change everything " $\mathrm{C} 1$

Couples also found it important to priotise and document what quality of life meant to them. This contributed to reflections about the positive things in life. In other words, to think about the good before the bad and not to worry in advance. Interestingly, one couple felt that contact with healthcare professional were too focused on identifying and teasing out problems rather than on health promoting activities:

"I think it is very important to think positively. It means very much to both of us that we think of what quality of life means to us and to think how good we really have it" $\mathrm{C} 4$

"I thought it was very nice that it [app name] was not problem-oriented because when you get to the hospital you get a little depressed but this was a 
271

272

273

274 Participation in the intervention contributed to positive emotions and couples felt that

275

276

277

278

279

280

281

282

283

284

285

286

287

288

289

290

291

292

293

294

295

thing where you highlight the positive and all that you can do. One does not have to be depressed in advance... It's a lot of good tips I think" C4 they had been involved in something valuable to other couples facing a similar

situation. The intervention and the follow-up study were perceived as a positive element in themselves and a feeling of being important:

"I can't say that it is only this...but the app is part of this ...It has felt good that we have been valuable in research ... that we can perhaps do something... for others who get a diagnosis" C3

\section{Discussion}

The aim of this study was to explore the experiences of the [app name] by couples where one partner has dementia living at home. The findings resulted in the themes:

Growth of the relationship, We are not alone, and Positive approach. The themes are clearly linked to couples recognition of their transition as a couple living with dementia. Here, transition can be defined as a passage from one life phase to another and describes a developing and often empowering change process as a consequence (Chick \& Meleis, 1986). In the presented study, the six couples' experiences of transition could be seen to have its starting point with the diagnosis of dementia, or when they suspected that something was wrong (the disconnectedness caused by the disruption), followed by phases of coping and adjustment to change (patterns of response), and the endpoint where couples have reached more stability relatively to the situation during the process (see also: Chick \& Meleis, 1986). However, dementia is a progressive condition which implies multiple transitions for couples and, perhaps, parallel transitions at the same time. The intensity of the influencing factor in a transition, in this case dementia, 
296 may also vary over the process and so might the patterns of response (Chick \& Meleis, 297 1986). However, the experiences of engaging in [app name] salutogenic and couple298 based approach to dementia and everyday life have positively impacted on couples and 299 their transition through the lived experience of dementia.

300 A growth of the couples' relationships comes from within an evolving process and time 301 span, couples in our study shared that dementia had changed their relationship in both 302 good and bad ways. Since this study targetted the present situation, we were interested 303 in how couples experienced everyday life whilst engaging with [app name].

304 Consequently, the theme 'Growth of the relationship' included a "we are in this

305 together" style of approach. Here, couples viewed dementia as a dyadic condition that 306 affected them both equally. Partners' interdependence on one another had also become 307 clearer over time and where the well-being of both mattered. Coping with the present, 308 and the future, as a unit was an important outcome in engaging with the [app name].

309 However, whilst dementia had brought partners closer to each other insofar as

310 they spent more time together, it also resulted in a heightened sense of togetherness and 311 mutual respect for their relationship (Hellström, Nolan, \& Lundh, 2005). For example, 312 in our study couples now described their relationship as 'more equal' and 'accepting'

313 and this was achieved by sharing responsibilities in areas that could previously be seen

314 as stereotypical gender role around the home, such as cooking and cleaning. Changes in

315 social and domestic roles have been studied by several researchers where relationships

316 often are described in terms of loss in relationship quality and former roles of the

317 relationship (Ablitt et al. 2009; Allen et al. 2017; Conway et al. 2018; Watson,

318 Tatangelo \& McCabe, 2018; Brodaty \& Donkin, 2009). However, the couples in our

319 study who expressed greater togetherness and role equality since the onset of dementia,

320 had come to terms with the situation and the ongoing transitional impact on their 
321 everyday lives. Accordingly, our study has demonstrated that there are positive aspects

322 of change in social roles and that this impacts upon relationship quality: a positive when

323 perhaps for too long, the experience of living with dementia has been socially

324 constructed as one of a diminishing number of contacts and connections (see for

325 example: Duggan, Blackman, Martyr, Van Shaik, 2008; Ward, Clark, Campbell,

326 Graham, Kullberg et al. 2018).

327 Interesting, the discussion about reaching a more equal relationship mainly came

328 up with couples where the husband had dementia, which might relate to former

329 structures of the domestic relationship (Boyle, 2017). Interestingly, older caregiving

330 husbands to a wife with dementia often felt that they had to give up some of their

331 masculine identity in order to take over "female chores" (Hellström, Håkansson,

332 Eriksson \& Sandberg, 2017). On the other hand, another experience of [app name] that

333 contributed towards a growth of the relationship, was when couples shared their

334 emotions and experiences of the impact of dementia on their relationship with each

335 other. It was a surprise that they had not done this before, a finding which we were not

336 expecting. Fear of revealing emotions to one another was one reason the couples gave

337 for this non-disclosure. However, by sitting down together with their mutual "task" of

338 talking about their feelings, the exercise gave the couple a neutral and accepting space

339 to talk about emotions; an experience that brought them closer together with a greater

340 understanding about different responses to coping with changing situations. This was

341 also the case when they discussed their communication and interaction with each other.

342 Talking about 'what works' and 'what does not work' and what contributes to conflicts

343 in their relationship helped couples to identify situations they could avoid and strategies

344 to put into place to enhance their quality of life and wellbeing. This brought a greater

345 awareness of their responses to situations which occur, and how their responses 
346 impacted on each other. Awareness is a key component in the concept of transition and

347 relates to the definitions and redefinitions of self and the situation (Chick \& Meleis,

348 1986). Indeed, 'talking things through'with each other as a couple has been highlighted

349 as an important part for growth of the relationship within couples where one partner has

350 dementia (Hellström et al. 2017) and data from this study would appear to support this

351 assertion.

352 The salutogenic approach to guide health and wellbeing and the focus on what couples

353 can do, rather on what they cannot do, permeated couple's discussions. Couples liked

354 the idea of focusing on positive resources and stated that there was currently too much

355 negativity around dementia. When documenting their inner resources and strengths

356 (included in [app name]), couples often came to the conclusion that they planned to do

357 more of the activities they like and know that they can manage. However, through the

358 use of [app name], couples also tried to learn new things, which meant that they

359 embraced a self-management approach and the everyday technology that made it

360 meaningful in their lives. Couples found it empowering to have performed tasks in the

361 app, both together and on their own. For people living with dementia as part of the

362 couple relationship, independent use of the [app name] depended upon the symptoms of

363 dementia and how advanced it was. According to LaMonica et al. (2017), older people

364 and people with cognitive decline, are often curious of internet and digital interventions

365 and how it might be possible to improve their situation. Furthermore, Stockwell-Smith

366 (2019) has examined couples' where one partner has dementia conditions for self-

367 management and found that with the support from healthcare staff, self-management

368 interventions can improve self-efficacy and independence. 
370 The use of everyday technology has been highlighted to positively influence people

371 with dementia and partners in their daily life (Gibson, Dickinson, Brittain \& Robinson,

372 2015), especially when people with dementia and their care partners have a sense of

373 familiarity to the technology, such as through a smartphone or tablet (Gibson et al.

374 2015; Newton, Dickinson, Gibson, Brittain \& Robinson, 2016). However, the

375 personalisation of technology and how it is used should be individually adapted (Gibson

376 et al. 2015), particuarly when that technology helps the person with dementia to

377 maintain activity (Rosenberg, Kottorp \& Nygård, 2012). Whilst this study did not focus

378 on the technology behind [app name], but on the self-management approach that is

379 often delivered via technology, the findings demonstrated that technology can be used

380 to support both couple relationships and activity.

The awareness of the progressive nature of dementia, and that couples know that

382 they probably are going to meet challenges (and transitions) over time, did not seem to

383 affect them in the present. In line with the findings of (Author, 2018a), couples often

384 live in the 'here and now' as a deliberate coping strategy to push to one side anxieties

385 and self-doubts. Couples involved in our study also pointed out that life is not over just

386 because a diagnosis of dementia is received. Whilst there is no denying that dementia is

387 a serious condition, people with dementia and their partners would perhaps benefit

388 more from the implementation of a salutogenic approach in healthcare.

389 This study has some limitations to consider. We interviewed six couples that

390 tested the app. According to Guest et al. (2006), there is no consensus in how many

391 participants required for a qualitative study. The recommendation is six to eight

392 participants as a minimum. This could contribute to a narrower picture of the

393 experiences of testing [app name] as a couple. Another limitation, is that we conducted

394 dyadic interviews (Sohier, 1995). Dyadic interviewing can result in fragmented data in 
395 case partners feel limited to speak freely in front of each other (Zahrin, 2018). However,

396 the method also help the partners with dementia to speak when they can be supported by 397 the partner.

\section{Conclusion}

399 The findings of this study indicate that couples where one partner has dementia value

400 interventions that focus on a salutogenic approach to their everyday life and

401 relationship. This dyadic intervention contributed to feelings of empowerment,

402 satisfaction of couples' achievements and a sense of support through both peers and the

403 intervention itself. The focus on strengths, resources and quality of life can give couples

404 insight into the growth of their relationship and the evolving transitions during the

405 trajectory of dementia. Furthermore, this study can serve as a starting point for the type

406 of support couples need and wish to receive. We therefore propose that further research

407 into couples where one partner has dementia sets out to embrace a more salutogenic

408 approach, one that is rooted in the couples' relationship and everyday life in order to

409 enhance overall well-being.

410

411

412

413

414

415 


\section{References}

419 Ablitt, A. Jones, G. V. \& Muers, J. (2009). Living with dementia: A systematic review of the influence of rela- tionship factors. Aging \& Mental Health, 13, 497-511.

Allen, P. A. Curran, A. E. Duggan, A. Cryan, J. F. Chorcora', A. N. Dinan, T. G. \& Clarke, G. (2017). A systematic review of the psychobiological burden of informal caregiving for patients with dementia: focus on cognitive and biological markers of chronic stress. Neuroscience and Biobehavioral Reviews, 73, 123-164.

426

Alzheimer's Disease International. (2009). World Alzheimer report. London: Alzheimer's Disease International.

Alzheimer's Disease International. (2013). World Alzheimer report. London:

Alzheimer's Disease International.

Alzheimer's Disease International. (2016). World Alzheimer report. London:

Alzheimer's Disease International.

432

Author $2017 \mathrm{a}$

433 Author, 2017b

434 Author, 2018a

435 Author 2018b

436 Barlow, J. Wright, C. Sheasby, J. Turner, A. \& Hainsworth, J. (2002). Self-management approaches for people with chronic conditions: A review. Patient Education and Counseling, 48, 177-187. .

Boyle, G. (2017). Revealing gendered identity and agency in dementia. Health and Social Care in the Community, 25,1787-1793.

441 Braun, V. \& Clarke, V. Thematic analysis. In H. Cooper (Ed.), APA Handbook of 442 Research Methods in Psychology (Vol. 2 Research Designs), 2012; New York:

443 American Psychological Association.

444 Braybrook, D. Mróz, L. Robertson, S. White, A., \& Milnes, K. (2017). Holistic

445 experiences and strategies for conducting research with couples. Qualitative $446 \quad$ Health Research, 27, 584-590. 
447

448

449

450

451

452

453

454

455

456

457

458

459

460

461

462

463

464

465

466

467

468

469

470

471

472

473

474

475

476

477

478

479

480

Chick, N,. \& Meleis A. I. 1986. Transitions: A Nursing Concern. https://repository.upenn.edu/cgi/viewcontent.cgi? article $=1008 \&$ context $=$ nrs (last accessed 19 August).

Chiu, TM. \& Eysenbach, G. (2011). Theorizing the health service usage behaviour of family caregivers: a qualitative study of an internet-based intervention. International Journal of Medical Informatics , 80, 754-64.

Conway, E.R. Watson, B. Tatangelo, G. \& McCabe, M. (2018). Is it all bleak? A systematic review of factors contributing to relationship change in dementia. International Psychogeriatrics, 30, 1619-37.

Dewing, J. (2008). Process consent and research with older persons living with dementia. Research Ethics Review, 4, 59-64.

Duggan, S. Blackman, T. Martyr, A. \& Van Shaik, P. (2008). The impact of early dementia on outdoor life a shrinking world? Dementia, 7, 191-204.

Gibson, G. Dickinson, C. Brittain, K. Robinson, L. (2015). The everyday use of assistive technology by people with dementia and their family carers: A qualitative study. BMC Geriatrics, 15, 89.

Grady, P. A. \& Gough, L. L. (2014). Self-management: a comprehensive approach to management of chronic conditions. American journal of public health, 104, 2531.

Guest, G. Bunce, A. \& Johnson, L. (2006). How Many Interviews Are Enough? An Experiment with Data Saturation and Variability. FIELD METHODS, 59 - 82.

Heehyul, M. Townsend, A.L. Whitlatch, C.J \& Dilworth-Anderson, P. (2017). Quality of Life for Dementia Caregiving Dyads: effects of Incongruent Perceptions of Everyday Care and Values. Gerontologist, 57, 657 - 666.

Hellström, I. Nolan, M.,\& Lundh, U. (2005). We do things together: A case study of 'couplehood in dementia. Dementia, 4, 7-22.

Hellström, I. Nolan, M. \& Lundh, U. (2007). Sustaining “couplehood”: Spouses strategies for living positively with dementia. Dementia, 6, 383-409.

Hellström, I. Håkansson, C. Eriksson, H. \& Sandberg, J. (2017). Development of folder men's caregiving roles for wives with dementia. Scandinavian Journal of Caring Sciences, 4, 957 - 964.

Huis in het Veld, J.G. Francke, A.L. Verkaik, R. \& van Meijel, B. (2018). A systematic review of self-management support for people with dementia. Dementia, 47130121877289. 10.1177/1471301218772894. 
481

482

483

484

485

486

487

488

489

490

491

492

493

494

495

496

497

498

499

500

501

502

503

504

505

506

507

508

509

510

511

512

513

Ibrahim, J. Anderson, L. MacPhail, A. Lovell, J. Davies, M. \& Winbolt, M. (2017). Chronic disease self-management for persons with dementia, in a clinical setting. Journal of Multidisciplinary Healthcare, 10, 49-58.

Lamonica, H. English, A. Hickie, I. Ip, J. Ireland, C. West, S. Shaw, T. Mowszowski, L. Glozier, N. Duffy, S, A. Gibson, A. \& Naismith, S. (2017). Examining Internet and eHealth Practices and Preferences: survey Study of Australian Older Adults With Subjective Memory Complaints, Mild Cognitive Impairment, or Dementia. Journal of Medical Internet Research, 19, 358.

Martin, F. Turner, A. Wallace, L. M. Choudhry, K. \& Bradbury, N. (2013). Perceived barriers to self-management for people with dementia in the early stages. Dementia, 12, 1-13.

Martire, L. M. Schulz, R. Helgeson, V. S. Small, B. J. \& Saghafi, E. M. (2010). Review and meta-analysis of cou- ple-oriented interventions for chronic illness. Annals of Behavior Medicine, 40, 325-342.

National Board of Health and Welfare (2014) The social costs of dementia in Sweden. Stockholm, Socialstyrelsen, 2014.

Newton, L. Dickinson, C. Gibson, G. Brittain, K. \& Robinson, L. (2016). Exploring the views of GPs, people with dementia and their carers on assistive technology: a qualitative study. BMJ Open, 6, Art. No.: e011132.

Official Report of the Swedish Government. (2016). Final report of a national coordinator for more efficient use of resources in health care, 2016. http://www.sou.gov.se/wp-content/uploads/2016/01/SOU-2016_2_Hela4.pdf.

Purkis, M. \& Ceci, C. (2015). Problematising care burden research. Ageing and Society, $35,1410-1428$.

Rosenberg, L. Kottorp, A. \& Nygård, L. (2012) readiness for technology use with people with dementia: The perspectives of significant others. Journal of Applied Gerontology, 31, 510-530.

Sinclair, C. Auret, K.A. Gersbach, K. Hogan, M. Bucks, R.S. Clayton, J.M. Agar, M.R. $\&$ Kurrle, S. (2018). How couples with dementia experience healthcare, lifestyle, and everyday decision-making. International Psychogeriatrics, 30, $1639-1647$. 
514 Stockwell-Smith, G. Moyle, W. \& Kellett, U. (2019). The impact of early-stage 515 dementia on community-dwelling care recipient/carer dyads' capacity to 516 self-manage. Journal of Clinical Nursing, 28, 629-640.

517 Ward, R. Graham, B. Manji, K. Rummery, K. Clark, A., Cambell, S., . . Kullberg, A.

518 (2018). The lived neighborhood: Understanding how people with demen- tia 519 engage with their local environment. International Psychogeriatrics 1

520 World Health Organization. (2016). Dementia. Fact sheets. Retrieved from 521 http://www.who.int/media centre/factsheets/fs362/en/ 522 World Medical Association. (2013). WMA declaration of Helsinki-Ethical principles 523 for medical research involving human subjects.

524 Zarhin, D. (2018). Conducting joint interviews with couples: Ethical and 525 methodological challenges. Qualitative Health Research, 28, 844-854. 
2 Table 1. Participant characteristics

\begin{tabular}{|lllllll|}
\hline & Couple 1 & Couple 2 & Couple 3 & Couple 4 & Couple 5 & Couple 6 \\
\hline $\begin{array}{l}\text { Gender } \\
\text { PwD/P }\end{array}$ & $\mathrm{F} / \mathrm{M}$ & $\mathrm{M} / \mathrm{F}$ & $\mathrm{M} / \mathrm{F}$ & $\mathrm{M} / \mathrm{F}$ & $\mathrm{M} / \mathrm{F}$ & $\mathrm{M} / \mathrm{F}$ \\
\hline Age PwD/P & $66 / 64$ & $81 / 83$ & $70 / 66$ & $79 / 78$ & $74 / 69$ & $72 / 68$ \\
\hline Diagnosis & $\mathrm{Alz}$ & $\mathrm{Alz}$ & $\mathrm{FTP}$ & $\mathrm{Alz}$ & $\mathrm{UNS}$ & $\mathrm{Alz}$ \\
\hline $\begin{array}{l}\text { Lenght of } \\
\text { relationship } \\
\text { (Years) }\end{array}$ & 40 & 60 & 45 & 60 & 40 & 50 \\
\hline
\end{tabular}

$3 \mathrm{PwD}=$ Person with Dementia, $\mathrm{P}=$ Partner, Alz $=$ Alzheimer's, FTP $=$ Fronto Temporal Dementia,

$4 \quad \mathrm{UNS}=\mathrm{Un}$ Specified Dementia

5 Table 2. Interview guide

How did you experience testing $\mathrm{xx}$ together?

Did you find anything positive about $\mathrm{xx}$ ?

Did you find anything negative about $\mathrm{xx}$ ?

Has xx contributed (good or bad) to your relationship, as a couple?

Did you use any information from xx, (how did you use it?)

6 